\title{
Advantages of a standard method for research on reproductive effects of occupation
}

\author{
MICHAEL JOFFE \\ From the Department of Community Medicine, St. Mary's Hospital Medical School, London W2
}

SUMMARY A recent review of the literature identified several common methodological weaknesses in studies of the effects of occupational exposures on male and female reproductive processes. This paper suggests a strategy which addresses these problems, by the use of a standard method. The potential benefits include increased measurement reliability and statistical power, together with a systematic study of expected (background) rates, confounding effects, types of exposure and selection effects. Particular advantages are the avoidance of designating a group as non-exposed with attendant problems of bias, and in the longer term the study of multiple or rare exposures.

There is considerable public anxiety about possible occupational hazards affecting fertility and pregnancy outcome. Reports of clusters of reproductive failure are becoming increasingly common, and there are enough reports of adverse reproductive outcomes associated with exposure of experimental animals or of humans to warrant further research into this important field. Ill-founded anxiety can affect employment policies and can cause considerable personal suffering, and it is clearly important to identify and remove proven hazards.

A comprehensive recent review $^{1}$ of reports published since 1981 included 27 case control studies, 12 sperm studies and 39 surveys of occupationallydefined populations. Several common weaknesses were identified in the methods used. These were inadequate sample size, inappropriate control groups, inadequate attention to potentially confounding factors, poor characterisation of exposures, low response rates, and potential for recall and selection biases. Although these problems may not have occurred in every study, their frequency indicates the magnitude of the task faced by all researchers in this field.

The purpose of this paper is to address the need for an improved method, in the context of surveys of occupationally-defined populations, both of male and female workers. The cornerstone is the use of a core questionnaire together with a standard approach to coding and analysis of data.

\section{Advantages of a standard method}

RELIABILITY OF OUTCOME VARIABLES

The need for reliable information has led some authors to conclude that questionnaire data should be verified using central registers or hospital records, particularly for certain outcome variables including miscarriages, ${ }^{2-4}$ birth weight ${ }^{5}$ and congenital malformations. ${ }^{1}$ The main problem encountered in each case has been bias as a result of the tendency for non-exposed subjects to give less reliable replies 5 and/or to under-report events. ${ }^{1-3}$ This suggests that a research strategy which provides an adequate control population, but which does not rely upon non-exposed subjects, would make it acceptable to use outcome variables derived from questionnaire data. Such a strategy is described below.

A core questionnaire would need to be tested for reliability. The author's questionnaire is described elsewhere. ${ }^{6}$ It comprises a reproductive history, a history of occupational exposures and information on background and confounding variables; in addition, exposure data are obtained directly from the factories participating in the research. Reliability was found to be acceptable, or better, for the key variables.

\section{A SYSTEMATIC APPROACH TO DATA COLLECTION}

If a standard method is used for a number of related studies, the data can be pooled, with consequent improvement in statistical power. Attention must then be given to the question of weighting. ${ }^{78}$ Alternatively, data obtained in a standardised way can be examined for consistency.

Further, if research is designed in such a way that comparisons of the data are valid, subsequent study populations can be chosen to make the most of existing results. Thus, if a hypothesis has been tested and the results neither confirm nor convincingly reject 
it because the population size is insufficient, a further population with the same exposure can be studied in order to achieve a decision. A systematic standardised approach is more effective, and therefore a better use of resources, than inconsistency and fragmentation.

EXPECTED RATES OF REPRODUCTIVE OUTCOME Observed rates can be compared both with other rates generated by the same method, the strategy for which is outlined below, and by published rates where these exist. For some reproductive outcomes such as low birthweight and perinatal mortality, baseline rates are available for the country as a whole and for different regions. 9 This is not the case for some of the other outcome variables, for example miscarriages and infertile phases, for which comparable national data are not available. The principal benefit of using such external comparisons is the relatively greater statistical power for a given size of study cohort. However, it is essential also to make internal comparisons, which raises the problem of the selection of an appropriate comparison group in order to generate expected rates for each outcome variable. ${ }^{10}$

An important advantage of the systematic use of a standard method is that expected rates can be generated in the course of the research. Whereas a study of a single occupational group requires an unexposed group for comparison, this is not necessary if several different occupations are included in the population. The pooling of data makes possible a method which proceeds by means of progressive refinements, whereby exposure groups with negative findings are subsequently used as control groups. It is unlikely that a large proportion of exposures are bio-active in such a way that they affect reproductive outcomes. This assumption opens up the possibility of treating observed rates for certain agents as those expected for unexposed groups, once these agents have been adequately characterised as harmless. The aim of a systematic research programme therefore becomes one of separating agents into "possibly harmful" and "baseline" categories, with new populations being recruited in order to resolve the borderline issues. None of this is possible if heterogeneous methods are used.

Table 1 Outcome variables

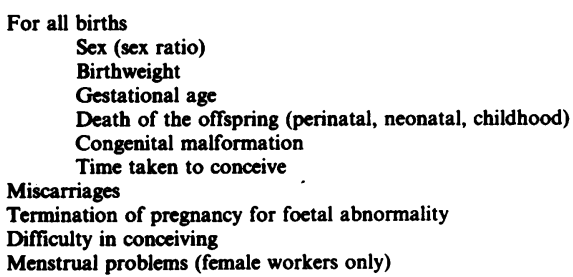

\section{CONFOUNDING EFFECTS}

The term "baseline" as used in the previous section may be misleading, as it encourages the assumption that a single baseline rate exists for each outcome variable, applicable to all populations. This ignores sources of variation other than the agents being studied. ${ }^{1} 1112$ Inter-regional variations (within Britain) have already been mentioned; other such confounding effects may include international variations and differences between populations in the distributions of ages of the parents, parity, consumption of tobacco, alcohol and pharmaceuticals, social class and educational level. Thus a further advantage of using a standard method is that the research programme can include a systematic study of all the confounding effects for which information is included in the questionnaire or is available from some other source.

\section{DERIVING EXPOSURE CATEGORIES FROM} OCCUPATIONAL GROUPS

The assessment of exposures requires a combination of approaches: information from questionnaires should be complemented by data supplied by the companies taking part in the study. ${ }^{11} 13$

As well as measurement issues, the subject of exposures raises a problem for analysis. Recruitment to a study is by occupational type rather than by pure exposure category. In general, occupational categories and exposure categories cross-cut one another: solvents, for example, are used in a variety of occupations, and in most of these the work also involves exposure to other agents. The importance of this distinction has been demonstrated by a study showing that an association of central nervous system malformations with exposure to solvents, which had already been demonstrated, disappeared when occupational titles were used as a proxy for exposure. ${ }^{14}$ A standard method allows data from different occupational groups to be pooled, and analysis can then be carried out by type of exposure.

Four further advantages accrue. Over-arching categories such as "solvents" can become progressively refined as more data accumulate. The analysis of exposure can progress from gross categories (no, low, high) to analyses with estimated doses. ${ }^{13}$ Multiple exposures can be analysed, for example by comparing groups exposed to solvents plus diazo compounds with those exposed only to solvents; an extension of this is the assessment of interactive effects. Rare exposures, applying only to a minority of people in each workplace, can be examined once sufficient numbers of workplaces have been studied. 
RECALL AND NON-RESPONSE BIAS

For reproductive outcome variables, the quality of well-collected retrospective interview data is generally satisfactory when compared with concurrently recorded information in hospital records; ${ }^{15-18}$ however, this does not hold if biasing effects are present. As mentioned above, such biases have been demonstrated, resulting from relatively inaccurate reporting by respondents in unexposed groups. The use of a standard method means that, since baseline information is partly derived from the study of populations exposed to agents subsequently found to be harmless, there is no need to rely on control groups designated as non-exposed. The substantial psychological difference between exposed and nonexposed status for participants in the study is no longer a barrier to obtaining reliable comparisons.

It is true that a more subtle variant can occur, that workers exposed to agents perceived as harmful may respond differently from those who have no anxiety about the possible reproductive effects of their working environment. The author's method includes a question on risk perception in order that this question can be studied empirically, and adjusted for if necessary. ${ }^{19}$

In order to minimise bias due to non-response, interviews are clearly preferable to self-completion questionnaires, ${ }^{17}$ despite the greater expense. In addition, response bias can be studied empirically as part of the study of baseline rates and their variation: after suspicious or harmful agents have been excluded, the association between each outcome variable and the response rate in that workplace or department can be measured. ${ }^{20}$ This is only feasible on pooled data.

\section{SELECTION EFFECTS}

For men, there is no reason to suppose that their reproductive health and their working lives interact in such a way that bias results. In the case of women, the situation is more complex. It is uncertain whether or not a "healthy worker effect" is to be expected for reproductive outcomes. The French national study of 1981 found no evidence for this, but the cross-sectional design of the research might have obscured such an effect. ${ }^{21}$ In a longitudinal study, women who reported poor health were less likely to have paid employment, ${ }^{22}$ but it is not clear whether such selfreports have any implications for reproductive function. This possibility has been raised in one study of spontaneous abortions, ${ }^{23}$ although other interpretations of the data shown seem to be more plausible. In any case, another investigation by the same authors ${ }^{24}$ has shown the opposite relationship, that economically inactive women have lower rates of spontaneous abortion.
More important than the interaction of working life with health is that with child-care responsibilities. ${ }^{19}$ There are four main effects. Since in many countries most women are absent from the workforce for some time after the birth of a child, any employed female population is likely to contain a proportion of relatively infertile women. Women who have young children and whose circumstances are desperate may be driven to go to work even though they would rather not do so, and as a result the effects of social deprivation are confounded with occupational effects. A similar but opposite confounding effect can occur among professional women, who are able to combine child-rearing with a career. Women who have a precarious pregnancy, or who are at very high obstetric risk, may avoid employment altogether. Such biases can be avoided if great care is exercised in the design and analysis of investigations, but this is only feasible in the context of a systematic research strategy using a consistent method.

\section{Conclusion}

A research strategy has been outlined, based on the use of a standard method analogous to those employed in other branches of epidemiology, for example the MRC respiratory questionnaire. ${ }^{25} 26$ It would enable several methodological problems in this area of research to be addressed, including selection effects and biases, the need to analyse data in terms of exposure categories rather than occupational descriptions, and the importance of a systematic study both of background rates and of confounding effects. This would also increase the effective size of the population studied.

\section{References}

${ }^{1}$ Rosenberg MJ, Feldblum PJ, Marshall EG. Occupational influences on reproduction: a review of recent literature. $J$ Occup Med 1987; 29: 584-91.

2 Axelsson G, Rylander R. Exposure to anaesthetic gases and spontaneous abortion: response bias in a postal questionnaire study. Int J Epidemiol 1982; 11: 250-6.

${ }^{3}$ Axelsson G, Rylander R. Validation of questionnaire reported miscarriage, malformation and birth weight. Int $J$ Epidemiol 1984; 13: 94-8.

${ }^{4}$ Heidam LZ, Olsen J. Self-reported data on spontaneous abortions compared with data obtained by computer linkage with the hospital registry. Scand J Soc Med 1985; 13: 159-63.

5 Tilley BC, Barnes AB, Bergstralh E, Labarthe D, Noller $\mathrm{KL}$, Colton T, Adam E. A comparison of pregnancy history recall and medical records. Am J Epidemiol 1985; 121: 269-81.

6 Joffe M. A questionnaire method for the study of reproductive effects of occupation. Submitted for publication. 
${ }^{7}$ Goldsmith JR, Beeser S. Strategies for pooling data in occupational epidemiological studies. Ann Acad Med 1984; 13: 297-307.

${ }^{8}$ Demets DL. Methods for combining randomized clinical trials: strengths and limitations. Statistics in Medicine 1987; 6: 341-8.

${ }^{9}$ OPCS. Mortality statistics, perinatal and infant (social and biological factors), 1985 Series DH3 no. 18. London: HMSO, 1987.

10 Gardner MJ. Considerations in the choice of expected numbers for appropriate comparisons in occupational cohort studies. La medicina del Lavoro 1986; 77: 23-47.

${ }^{11}$ Hemminki K, Axelson O, Niemi M-L, Ahlborg G. Assessment of methods and results of reproductive occupational epidemiology: spontaneous abortions and malformations in the offspring of working women. $\mathrm{Am} \mathrm{J}$ Ind Med 1983; 4: 293-307.

12 Cavedon G, Figa-Talamanca I. Correlates of early fetal death among women working in industry. Am J Ind Med 1987; 11: 497-504.

13 Lemasters GK, Selevan SG. Use of exposure data in occupational reproductive studies. Scand J Work Environ Health 1984; 10: 1-6.

${ }^{14}$ Holmberg PC, Hernberg S. Congenital defects and occupational factors: a comparison of different methodological approaches. Scand $J$ Work Environ Health 1979; 5: 328-32.

15 Joffe M, Grisso JA. Comparison of ante-natal hospital records with retrospective interviewing. J Biosoc Sci 1985; 17: 113-9.

${ }^{16}$ Hewson D, Bennett A. Childbirth research data: medical records or women's reports? Am J Epidemiol 1987; 125: 484-91.
${ }^{17}$ Cartwright A. Monitoring maternity services by postal questionnaire to mothers. Health Trends 1987; 19: 19-20.

${ }^{18}$ Seidman DS, Slater PE, Ever-Hadani P, Gale R. Accuracy of mothers' recall of birthweight and gestational age. $\mathrm{Br} J$ Obs Gynaecol 1987; 94: 731-5.

19 Joffe M. Biases in research on reproduction and women's work. Int J Epidemiol 1985; 14: 118-23.

${ }^{20}$ Chavance M. Essai de correction du biais du aux nonreponses. Rev Epidem et Sante Publ 1983; 31: 39-44.

${ }^{21}$ Stengel B, Saurel-Cubizolles M-J, Kaminski M. Healthy worker effect and pregnancy: role of adverse obstetric history and social characteristics. J Epidemiol Community Health 1987; 41: 312-20.

22 Waldron I, Herold J, Dunn D, Staum R. Reciprocal effects of health and labor force participation among women: evidence from two longitutinal studies. J Occup Med 1982; 24: 126-32.

${ }^{23}$ Hemminki K, Niemi M-L, Kyyronen P, Kilpikari, Vainio $H$. Spontaneous abortions and reproductive selection mechanisms in the rubber and leather industry in Finland. Br J Ind Med 1983; 40: 81-6.

${ }^{24}$ Hemminki K, Kyyronen P, Niemi M-L, Koskinen K, Sallmen M, Vainio $H$. Spontaneous abortions in an industrialised community in Finland. Am J Public Health 1983; 73: 32-7.

${ }^{25}$ Medical Research Council's Committee on research into chronic bronchitis. Questionnaire on respiratory symptoms. London: MRC, 1966.

${ }^{26}$ Holland WW, Ashford JR, Colley JRT, Morgan DC, Pearson NJA. A comparison of two respiratory symptoms questionnaires. Br J Prev Soc Med 1966; 20: 76-96. 